ESTUDos RBEP

\title{
Educação não escolar como campo de práticas pedagógicas
}

\author{
José Leonardo Rolim de Lima Severo ${ }^{\mathrm{I}, \text { II }}$
}

http://dx.doi.org/10.1590/S2176-6681/345513545

\section{Resumo}

Universidade Federal do Piauí (UFPI), Teresina, Piauí, Brasil. E-mail: leonardorolimsevero@ gmail.com

II Doutor em Educação pela Universidade Federal da Paraíba (UFPB), João Pessoa, Paraíba, Brasil.
Apresenta considerações acerca do conceito de educação não escolar (ENE) e, a partir delas, estabelece contribuições críticas ao debate que envolve o reconhecimento e o fortalecimento dos processos educativos que se inserem nesse âmbito, sob o entendimento da pedagogia como ciência da educação capaz de imprimir sentidos pedagógicos nesses processos. Admitindo a existência de dimensões formativas intrínsecas a diferentes relações e processos sociais influenciados por uma nova racionalidade educativa contemporânea, discute a perspectiva da sociedade pedagógica e da aprendizagem ao longo da vida, o lugar da ENE quanto às categorias descritivas do fenômeno educacional e os aspectos que a configura como cenário de práticas pedagógicas fundadas pela práxis da pedagogia.

Palavras-chave: educação não escolar; pedagogia; práticas pedagógicas; educação não formal. 


\section{Abstract \\ Non-school education as a field of pedagogical practices}

This study presents considerations concerning the concept of non-school education (NSE) and, based on them, establishes critical contributions to the debate related to the recognition and to the strengthening of educational practices inserted in this scope, under the understanding of Pedagogy as an Educational Science able to print pedagogical senses in these processes. Admitting the existence of intrinsic formative dimensions in different relationships and social processes influenced by a new contemporary educational rationale, we discuss the perspective of pedagogical society and lifelong learning, the place of the NSE in relation to the descriptive categories of educational phenomenon and the aspects that constitute it as a pedagogical practice founded by the praxis of Pedagogy.

Keywords: non-school education; pedagogy; pedagogical practices; non-formal education.

\section{Introdução}

Este artigo apresenta uma discussão que problematiza a aparente estabilidade de uma expressão corrente na literatura pedagógica desde a última metade do século passado: a educação não escolar (ENE). Observa-se que a recorrência discursiva que prolifera o uso dessa expressão sustenta a necessidade de destacar e reconhecer a emergência de novos cenários e práticas educativas na esteira do desenvolvimento das dinâmicas sociais contemporâneas. Do mesmo modo, é perceptível o baixo nível de preocupação da comunidade acadêmica em explorar os sentidos que essa expressão representa no contexto do debate socioeducacional, dando-lhe densidade e esclarecimento conceitual. Tal circunstância necessita ser superada pela intensificação de estudos e pesquisas que se voltem para os desdobramentos do movimento de fortalecimento da educação não escolar que, manifestando-se cada vez mais nitidamente, conta com processos institucionalizados em diversos setores sociais, passando a influenciar de modo mais incidente a formação humana.

A pedagogia, como ciência da educação interessada pelo fenômeno educativo em seu sentido amplo, para além da escola, é um campo de conhecimento que deve assumir, a partir de diálogos interdisciplinares, posição de protagonismo na construção de referenciais teóricometodológicos que possibilitem a potencialização de efeitos formativos decorrentes de práticas em espaços de ENE, convertendo-as em práticas pedagógicas.

A emergência da ENE como perspectiva de desenvolvimento de práticas formativas que atendem a demandas além-escola se insere em um contexto 
atravessado por fatores sociais, políticos e econômicos relativos ao processo de globalização, bem como por fatores culturais gerados pela impulsão da comunicação e pela troca de experiências apoiadas em tecnologias contemporâneas. Do ponto de vista teórico, a ENE se relaciona com conceitos correntes no campo da pedagogia que expressam um significado ampliado para a formação humana com base em processos de ensino e aprendizagem diversificados, complexos, dinâmicos e interconectados em espaços e tempos distintos da instituição escolar, a exemplo do conceito de educação permanente, educação ao longo da vida, educação integral, educação social etc.

Ao lado desses conceitos, algumas perspectivas que fornecem elementos para conceituar a ENE se destacam por abordarem fatores que caracterizam e explicam o sentido e o funcionamento da prática educativa na sociedade contemporânea, a exemplo da perspectiva da sociedade pedagógica, da sociedade educativa e da sociedade do conhecimento. Em particular, a perspectiva da sociedade pedagógica problematiza o aumento dos desejos de ensinar e aprender, ressaltando as necessidades de uso e geração de saberes em prol de ideais societários diversos.

\section{Sociedade pedagógica: pluralidade das práticas educativas e o lugar da educação não escolar}

A expressão "sociedade pedagógica" é cunhada por Beillerot (1985) para se referir à natureza da sociedade contemporânea, considerando a interface educativa presente nas dinâmicas das relações sociais. Esse autor argumenta que as dinâmicas de desenvolvimento econômico e político da sociedade serviram de base para a construção de uma cultura de uso dos saberes que ampliou os horizontes dos fins e dos meios educacionais, inflacionando as práticas pedagógicas e transportando-as do espaço escolar para outros nichos institucionais extraescolares. Essa sociedade intensifica os processos formativos e integra-os a outros processos sociais, tornando-os cenários de possibilidades de ensino-aprendizagem e requerendo pedagogias e políticas próprias para estruturar determinados ideais e mecanismos de formação dos sujeitos.

Desse modo, "certas práticas sociais cujas finalidades são próprias e específicas necessitam, para conseguir a sua missão, de integrar saberes e práticas pedagógicas" (Beillerot, 1985, p. 245). Essa forma de compreender a educação como um fenômeno plurifacetado e extensivo em diversas esferas da sociedade leva a crer na existência de possibilidades potenciais de promoção da educabilidade humana em face de demandas que marcam os contextos de inserção do sujeito nas dinâmicas sociais. Nesse sentido, pode-se dizer que, "nas várias esferas da sociedade, surge a necessidade de disseminação e internalização de saberes e modos de ação [...], acentuando o poder pedagógico dos vários agentes educativos na sociedade" (Pimenta; Anastasiou; Cavallet, 2003, p. 268). 
O século 21 é cenário de novas configurações pedagógicas que criam e recriam diferentes possibilidades de ensinar e aprender, tornando ainda mais complexo o significado e as formas de educação. Interessada em construir economias de conhecimento por meio da constituição de dispositivos educativos formais, não formais e informais, centralizando o saber em estratégias políticas, culturais e institucionais, a sociedade contemporânea é concebida por Beillerot (1985) como sociedade pedagógica.

As economias de conhecimento consistem em uma metáfora relativa à circunstância de investimento na produção, no acúmulo e no uso de saberesfazeres implicada em processos sociais diversificados que não se limitam às instituições e aos contextos historicamente orientados e interessados pela socialização e aplicação desses recursos, como a escola, a família, a religião etc. Guile (2008) ressalta que as necessidades de investimento em saber e formação humana criam uma cultura epistêmica em que a educação se expande para dar conta de socializar e estimular o desenvolvimento de conhecimentos plurais cujo fundamento se associa a interesses políticos, culturais e econômicos distintos.

Beillerot (1985) destaca que se trata de uma sociedade que desperta necessidades e desejos de ensino e aprendizagem, além de estabelecer dimensões pedagógicas nas relações sociais que lhe são constitutivas. E esclarece que "a ação pedagógica descobre-se no centro de um complexo desenvolvimento social e tecnológico, pelo que é ainda necessário investigar porque motivo as relações sociais assumem tanto a forma de relações pedagógicas" (Beillerot, 1985, p. 239).

A ideia de que "talvez nunca tenhamos tido em nossa história necessidade tão grande de ensinar, de estudar, de aprender mais do que hoje. De aprender a ler, a escrever, a contar" (Freire; Horton, 2003, p. 207) é explicada quando se considera que as instituições criaram necessidades de aprendizagem e de saber nos sujeitos. Daí a pertinência da análise feita por Beillerot (1985, p. 141) quando reflete que "a reprodução da necessidade de saber é uma forma socializada e, logo, em evolução, do desejo de saber, ele mesmo uma transformação do desejo de conhecer".

Importa dizer que grande parte dessas ações educativas emergentes configura uma ampla e complexa constelação de práticas inscritas fora do espaço escolar e que se estabelecem ao longo de toda a vida dos sujeitos. Sem negar o potencial e a especificidade da escola, as práticas educativas não escolares adquirem relevância no contexto de um projeto de sociedade em que a aprendizagem e o conhecimento ocupam lugares centrais.

\section{Educação não escolar e aprendizagem ao longo da vida}

A ENE corresponde a um termo cuja conceituação repousa em uma necessidade histórica emergente, dado o atual contexto de fortalecimento do caráter estruturado de práticas educativas para além dos limites da escola. Se, na maior parte do tempo, a pedagogia e a sociedade, em geral, deixaram de focalizar a ENE como problema pedagógico, a atualidade 
tem sido cenário de proliferação de iniciativas cada vez mais visíveis de desenvolvimento de processos formativos em espaços não convencionais de ensino e aprendizagem. Diversas instituições não escolares, porém com interesses educativos em sua conjuntura ou com algum tipo de inserção em contextos nos quais as pessoas necessitem atuar mediante o uso de ferramentas pedagógicas, têm configurado em sua agenda de trabalho objetivos e ações que manifestam, em maior ou menor medida, um caráter instrutivo, educativo ou pedagógico. Nesses novos cenários, não só são processadas novas práticas educativas, como também essas práticas põem em avaliação, direta ou indireta, a função da escola e das aprendizagens que se espera que sejam promovidas em seu âmbito. Ou seja, "mientras la institución escolar trata de realizar su tarea, otros setores también interesados en la educación, en su sentido más amplio, realizan sus programas e evaluan sus resultados" (Cuadrado Esclapez, 2008, p. 19).

Durante muito tempo, tais ações não eram configuradas como problemas ou processos pedagógicos, porque, como afirma Gohn (2010, p. 34), estão relacionadas à educação não formal, a qual consiste em uma área "que o senso comum e a mídia usualmente não veem e não tratam como educação porque não são processos escolarizáveis". Contudo, a ENE não se redunda, de modo arbitrário, à educação não formal. Esta última se constitui em categoria conceitual descritiva cuja aplicação serve para setorizar o fenômeno educativo, ao lado da educação formal e da educação informal.

Compreende-se que a ENE pode ser conceituada como uma categoria temática que engloba práticas consideradas formativas situadas fora da escola. É, portanto, mais adequada para se referir aos espaços educativos em que ocorrem processos não formais e informais, embora em alguns casos seja possível reconhecer atividades formais que se desenvolvem fora da escola, em contextos não convencionais. Do mesmo modo, a escola pode ser cenário de atividades educativas não formais, como ocorre no caso das práticas de educação social em instituições escolares, as quais configuram um campo em construção pelo esforço de inserir no contexto da escola, especialmente sob a perspectiva da educação integral, atividades de caráter educativo complementar e integrativo ao desenvolvimento do projeto político-pedagógico e do currículo, a exemplo de oficinas musicais, artísticas, esportivas e extensão comunitária.

Com base nesse ponto de vista, a ENE consiste na designação de espaços, contextos ou âmbitos sociais e institucionais distintos da escola em que práticas educativas estejam sendo desenvolvidas considerando os modelos formais, não formais e informais, nos diversos níveis de inter-relações que se supõe existirem entre esses modelos. Assim, sua funcionalidade conceitual se aplica diante da necessidade de denominar contextos de ação educativa, e não sumariamente descrever práticas educativas, uma vez que, para esta última tarefa, recomenda-se o uso das categorias descritivas do fenômeno educativo já mencionadas anteriormente: educação formal (EF), educação não formal (ENF) e educação informal (EI).

A adjetivação não escolar estabelece, a princípio, um caráter de negação à escola, o que pode remeter à ideia de que entre um e outro tipo 
de educação existe uma relação de contrariedade. Porém, torna-se mais adequado pensar no sentido da ENE não como uma oposição à escola, mas como uma forma de educação que se identifica por não ser distinta à escolar e que, com relação a esta, pode estabelecer interfaces de colaboração, complementaridade, associação e suporte.

A ENE se relaciona com o paradigma de aprendizagem ao longo de toda a vida, de modo que representa ações que prolongam os tempos e os espaços de formação e autoformação, com base em necessidades contextuais dos sujeitos e das comunidades, atuando como mecanismo catalisador da articulação de saberes diante de necessidades emergentes nas esferas das sociabilidades humanas e do trabalho. Considerando a noção de educação ao longo de toda a vida, propõe-se a ideia de que as divisões tradicionais de tempos e espaços para educar e educar-se devem ser superadas por meio da adoção de um paradigma dinâmico de educação, tida como um processo que acompanha a vida das pessoas, preparando-as para o seu exercício social, e como instrumento de potencialização de qualidades que lhes permitam maior bem-estar global. Esse paradigma se concretiza por meio de práticas educativas abertas, plurais e contextualizadas, em que a cultura e a experiência vivida pelo sujeito sejam a base para a construção de saberes e atitudes críticas e criativas. Nesse cenário, a ENE se converte num potente meio de operacionalização da concepção de que não se aprende exclusivamente em única fase da vida, nem sob a orientação de um currículo reduzido às aprendizagens escolares.

Fundamentada na ideia de educação ao longo de toda a vida, a ENE se configura como

[...] produto de uma dialética com várias dimensões [...]. Experiência singular de cada pessoa ela é, também, a mais complexa das relações sociais, dado que se inscreve, ao mesmo tempo, no campo cultural, no laboral e no da cidadania. (Delors. 1999, p. 107).

Torna-se necessário explicitar o que se configura como ENE, num esforço de definição conceitual, a fim de estabelecer o seu caráter diante de alguns outros conceitos correntes que se associam ao universo das práticas educativas fora da escola e, sobretudo, qual a sua localização entre as categorias clássicas de setorização do fenômeno educativo: educação formal, não formal e informal.

\section{O caráter da educação não escolar quanto às categorias de descrição do fenômeno educativo}

Conforme assinalado, o uso do conceito de ENE é mais adequado como uma categoria temática, ou situacional, visto que o objeto que ele busca delimitar se refere a um âmbito, uma situação ou um espaço educativo. Já as práticas, os processos e as ações não escolares poderão ser definidos de acordo com as três categorias descritivas do fenômeno educativo, embora, 
na maioria dos casos, as situações de educação não escolar coincidam com processos não formais.

O esclarecimento conceitual da ENE está ligado, portanto, a um aprofundamento acerca dos sentidos e relações entre educação formal, educação não formal e educação informal, o que implica uma discussão que, sem a pretensão de se constituir numa exaustiva abordagem sobre esse tema, situe as principais características e dinâmicas referentes a cada categoria. Porém, vale ressaltar que a ENE, como prática intencional e organizada, de fato se aproxima mais da educação não formal do que das outras duas categorias. Então, privilegiar-se-á uma discussão mais precisa sobre o significado da educação não formal, considerando que grande parte das práticas de educação não escolar manifestam características que as permitem ser enquadradas como processos não formais.

Embora o uso das categorias mencionadas não goze de um consenso entre pesquisadores e profissionais da área da pedagogia, considera-se que elas correspondem a uma necessidade histórica de delimitação conceitual no âmbito dessa ciência em face do aprofundamento das diferenças entre as práticas educativas e o progressivo reconhecimento das suas especificidades e, consequentemente, da sua legitimidade e importância no contexto geral dos meios e instrumentos de formação humana.

Compreende-se que, para além da polêmica que envolve a primazia de um ou de outro critério de classificação das práticas, de forma isolada ou combinada, essas categorias servem para setorizar os diferentes processos educativos, reconhecendo novas modalidades de intervenção formativa e ressaltando sua localização no universo da educação como prática social. Ademais, apresentam a possibilidade de operar com uma classificação pedagógica que se desliga da centralidade que fez com que a escola se tornasse, durante muito tempo, a forma mais típica e mais importante de formação humana. Com efeito,

[...] essa instituição foi alçada a paradigma da ação educativa a tal ponto que o objeto da reflexão pedagógica (tanto teórica quanto metodológica e instrumental) se foi limitando mais e mais a ela, até produzir uma espécie de identificação entre "educação" e "escolarização". (Trilla, 2008, p. 17).

Os conceitos de educação formal, educação não formal e educação informal foram apresentados à literatura pedagógica pelo livro intitulado The World Educational Crisis, de P. H. Coombs, em 1968 (editado em língua portuguesa no ano de 1976). Esse livro foi totalmente reescrito e relançado em 1986 com o título A crise mundial da educação.

Como sublinham Trilla (2008), Trilla, Gros, López e Martín (2011) e García Aretio, Ruiz Corbella e García Blanco (2009), o surgimento dessas categorias acontece em um contexto histórico que se liga ao transcurso das décadas 60 e 70 do século 20. Naquele momento, organismos e setores sociais sugeriam a necessidade de corresponder às demandas sociais da educação mediante mecanismos educativos situados fora do marco escolar, visto que a escola passou a ser alvo de críticas quanto à sua finalidade formativa. Primeiramente, as análises macroeducativas denunciavam a 
insuficiência da escola para atender a um universo de demandas e populações com necessidades específicas geradas por mudanças sociais e econômicas. Acreditava-se que, ainda que os sistemas escolares tivessem crescido em quantidade e qualidade, o seu modo convencional de abordagem formativa não parecia ser adequado para desenvolver aprendizagens numa sociedade em transição de valores, ideais e horizontes de futuro.

Trilla, Gros, López e Martín (2011) sublinham que, junto com as análises macroeducativas baseadas em referenciais sociológicos, surgiram também, coincidentemente, reflexões fundadas em perspectivas que questionavam aspectos radicais do funcionamento e da cultura escolar. Expressões como "escola autoritária", "escola tradicional" e "escola classista" se reportam a uma série de abordagens críticas que se voltavam para os processos que configuram a identidade e a dinâmica da escola.

As análises desdobradas desde então parecem reconhecer que, embora a escola se mantenha no centro da representação sobre o que é educação e sobre o fator educativo, o estabelecimento escolar constitui um arranjo institucional histórico que nem sempre existiu, e nada garante que perdure para sempre; que a escola é um momento do processo educativo na vida da sociedade, mas que esse processo é global e envolve outros espaços e tempos sociais; que os efeitos formativos da escola nas pessoas se vinculam a aprendizagens decorrentes de outros contextos nos quais elas estão inseridas, não conformando, desse modo, a influência determinante em sua constituição como sujeito individual e social; que a identidade social da escola serve para operacionalizar alguns objetivos pedagógicos e não todos; e que, para potencializar tais objetivos, torna-se necessário estabelecer meios de interligação entre escola e outros espaços educativos, em caráter complementar, integrativo ou paliativo.

A abertura para compreender esses processos educativos não escolares, à luz de demandas sociais que envolvem o momento histórico, proporciona a consolidação de uma perspectiva de conceituação da educação como um fenômeno complexo, disperso, heterogêneo, sobre a qual se denomina uma multiplicidade de práticas e resultados formativos. Na medida em que essa perspectiva se instalou na literatura pedagógica, surgiu a necessidade de aplicar critérios para discriminar modalidades de práticas educativas. Nesse sentido, tornam-se pertinentes as categorias de $\mathrm{EF}$, ENF e EI, ainda que os critérios utilizados para demarcar as fronteiras que delimitam cada uma delas não sejam convencionados univocamente.

A perspectiva clássica de definição de EF, ENF e EI, que é a de Coombs, define, conforme Trilla (2008), a EF como os processos altamente institucionalizados, cronologicamente graduados e com uma hierarquia que compreende a seriação escolar dos primeiros anos de educação infantil até os últimos da universidade; a ENF como o conjunto de atividades que, embora formalizadas e com intencionalidade educativa explícita, são realizadas fora do sistema educativo oficial; e a EI como 
por meio de experiências diárias e de sua relação com o meio. (Coombs, 1975, p. 27 apud Trilla, 2008, p. 33).

Trilla, Gros, López e Martín (2011) esclarecem que essas categorias podem ser aplicadas segundo critérios distintos, como com relação a conteúdo, procedimentos metodológicos, espaços e objetivos das práticas educativas, embora concordem que os critérios que demarcam com maior precisão as fronteiras entre elas podem ser o da diferenciação e o da especificidade. Para justificar a adoção desse critério frente aos que normalmente são aplicados para delinear as categorias, quais sejam, o critério metodológico e o da intencionalidade, eles explicam que é errôneo equiparar as três categorias, supondo que cada uma delas detém metodologias educativas específicas e exclusivas ou que se referem a uma graduação de fator de intencionalidade em que a EF seja a que apresenta um maior grau e a EI pouco ou nenhum grau.

Desse modo, os autores, em concordância com Touriñan Lopez (1983), acreditam que o critério de diferenciação se aplica para distinguir as práticas educativas formais das não formais, enquanto que o da especificidade situa as práticas informais com relação às demais. Esses critérios correspondem a uma tentativa de superação do equívoco que é considerar que a EF e ENF detém graus de sistematização e organização distintos entre si, bem como que a EI não é intencional. A EF e a ENF estão agrupadas em um mesmo nível por serem, ambas, sistematizadas por intencionalidades explícitas, assim como por apresentarem organização metodológica. Entre si, diferem apenas no sentido de que a EF corresponde ao ensino oficial e a ENF, às práticas educativas intencionais e sistemáticas que não conferem certificação oficial compatível ao sistema de títulos acadêmicos.

A EI difere das demais em virtude de se referir a processos que não têm uma função educativa especificada, embora haja intencionalidades formativas permeando-os, como no caso da educação familiar, dos impactos educativos das mídias etc. As práticas informais exercem influências educativas, porém o caráter educativo se submete às razões primordiais dessas práticas e, portanto, não adquire especificidade. Essas práticas não se desdobram de um processo em que haja decisões quanto ao tempo, ao espaço, ao conteúdo, às metodologias para operacionalizar objetivos educativos. Elas ocorrem espontaneamente ou como efeito secundário desdobrado de processos diversos dos quais não se diferenciam e por meio deles levam as pessoas a adquirirem conhecimentos, hábitos, modos de percepção da realidade com base na experiência e nas amplas relações sociais.

Os processos formais e não formais, por sua vez, são diferenciados e específicos, e a distinção entre eles não se justifica, de modo arbitrário, pelo critério metodológico - já que atualmente a transposição de metodologias entre um e outro tipo de educação ocorra com maior fluxo - nem pelo critério estrutural. Este último implicaria a definição do tipo de educação quanto a sua localização na estrutura administrativa dos sistemas de ensino. Se a prática estivesse fora do âmbito dessa estrutura, seria não formal 
e, por conseguinte, caso se inscrevesse em seus domínios, seria formal. Desse modo, o formal seria escolar e o não formal, consequentemente, seria não escolar.

A delimitação resultante do uso desse critério necessita ser relativizada, visto que a presença ou a ausência de determinadas práticas na estrutura oficial de administração do ensino ocorre em virtude de necessidades históricas, portanto, a relação arbitrária que torna equivalente a EF e a educação escolar, por um lado, e a ENF e a ENE, por outro, é um equívoco. De todo modo, o critério estrutural serve para identificar que as práticas são formais quando seus resultados são enquadrados segundo o sistema oficial de certificação acadêmica.

Reconhecendo a aproximação que existe entre a ENE e a ENF, mas considerando que essa correlação é uma manifestação histórica e que a própria dinâmica social pode converter práticas não formais em práticas escolarizadas, passa-se, então, a centralizar algumas características mais típicas da ENF, a qual atualmente é a manifestação mais usual de práticas educativas não escolares que atendem a objetivos formativos diferenciados e específicos.

A ENF está a serviço da formação das pessoas para a aquisição de saberes e a construção de práticas assinaladas por demandas de aprendizagens para o ócio, para o trabalho, para a participação social etc. Ela se ajusta contextualmente aos espaços e tempos socioeducativos por possuir um caráter flexível que a torna permeável a um amplo espectro de conteúdos e metodologias didáticas.

As perspectivas que organizam os processos em ENF constituem um discurso pedagógico que, em geral, valoriza a experiência prática dos sujeitos em formação, saberes pré-adquiridos à escola e não convencionais, metodologias abertas e um marco avaliativo mais dinâmico. Entretanto, é possível encontrar, naturalmente, processos que divergem dessa orientação por estarem fundamentados em perspectivas instrumentais, tecnicistas e burocráticas, sobretudo vinculadas ao modelo de treinamento, as quais atendem muito mais os objetivos de produtividade das instituições do que servem para potencializar a educabilidade dos sujeitos e sua capacidade de ação individual e social.

Por estar associada a contextos mais diversificados, a ENF lida com uma pluralidade de saberes e formas de conhecimento, o que abre possibilidades para que, em alguns casos específicos, os seus agentes não necessitem ser portadores de qualificações acadêmicas oficiais.

Por considerar a intensa pluralidade de práticas em ENF e, consequentemente, a ampla gama de espaços, conteúdos, objetivos e sujeitos que ela abrange, torna-se impossível asseverar características globalmente notáveis nos fenômenos que lhe estão associados. Importa dizer, nesse sentido, que o conceito de ENF se encontra aberto às mudanças e peculiaridades que os sentidos das práticas formativas exercidas sob sua denominação poderão introduzir. Trilla, Gros, López e Martín (2011) descrevem que as principais áreas de atuação da ENF são educação de adultos, educação laboral e formação ocupacional, educação para, em e 
no contexto do ócio, animação sociocultural, educação em grupos com especificidades sociais especiais, educação ambiental, cívica, sanitária, pedagogia hospitalar, educação sexual, física, artística, para a manutenção do patrimônio cultural, educação em valores etc.

A mutação que gera novas manifestações em ENF tem se tornando mais evidente desde a década de 1990, momento em que se percebe a consolidação de uma cultura educativa que exprime significados plurais para o processo de formação humana, promovendo o reconhecimento de novas formas de ensino e aprendizagem que passam a se proliferar em diversos tipos de organização.

A partir dessa discussão sobre o conceito de ENE e sua relação com a EF, a ENF e a EI, desdobram-se questões sobre como os processos formativos não escolares se configuram em ações pedagógicas, no sentido de serem fundamentados em matrizes da teoria pedagógica. Tais questões merecem especial atenção porque apontam para aspectos que revelam características acerca do modo pelo qual as práticas em ENE podem se configurar como cenários de ação profissional do pedagogo e, não obstante, como objeto de investigação pedagógica.

\section{Práticas pedagógicas em educação não escolar}

Partindo de uma conceituação acerca do que se configura como prática pedagógica, pretende-se ressaltar aspectos que evidenciam os potenciais que a pedagogia possui para, mediante a intervenção do pedagogo, imprimir sentido aos processos educativos não escolares, organizando-os por meio de uma abordagem complexa que compreende amplo espectro de variáveis relativas às fases que constituem esses processos e ao contexto histórico, cultural, social e intersubjetivo no qual estão inseridas.

A pedagogia, como ciência da educação, desenvolveu, ao longo de sua história, sistemas teórico-metodológicos com foco nas práticas educativas em suas diversas dimensões. Embora seja comum associar o conhecimento em pedagogia à escola, ou ao ensino de crianças, os conhecimentos pedagógicos se constituem em importantes ferramentas que proporcionam modos de compreensão e intervenção em situações educativas diversas. Esse conhecimento, que é teórico e prático ao mesmo tempo, dada a natureza práxica da pedagogia, funciona como uma chave de reflexão e proposição educativa, dotando os sujeitos de recursos que lhes permitam formular estratégias de ação com base no reconhecimento de objetivos e fatores que exercem influências nas práticas que desenvolvem, racionalizando-as sistematicamente. Trata-se de um importante suporte que adquire sentido a partir da reflexão sobre a prática e que, ao mesmo tempo, opera, por meio da compreensão crítica da prática com base em princípios da pedagogia, a conversão de uma prática educativa em prática pedagógica.

Ou seja, o conhecimento pedagógico aplicado e construído em diálogo com as demandas da prática produz e especifica uma dimensão dos 
processos educativos que, naturalmente, eles não possuem: a reflexividade com base em ideias pedagogicamente sistematizadas. Considera-se, então, que é por meio da reflexão que se fundamenta na pedagogia e que é sistematicamente organizada com base em seus princípios, consistindo como um modo de intervenção do conhecimento científico na realidade, que uma prática educativa se converte em prática pedagógica. A prática pedagógica é resultante da práxis da pedagogia exercida na realidade da prática educativa, guiada pelo objetivo de potencializar a educabilidade humana em face de uma perspectiva ampla de desenvolvimento social, mais além das limitações impostas pelos interesses econômicos de capitalização da formação dos sujeitos, enquadrando-a segundo as necessidades do mercado.

Esse ponto de vista reforça o sentido orientador das práticas educativas configurado na pedagogia e valoriza a ação dos profissionais que aplicam e constroem conhecimentos pedagógicos nos diversos contextos e cenários da educação escolar e não escolar. Igualmente, nega a perspectiva que identifica prática educativa sumariamente com prática pedagógica, ignorando a diferenciação que se estabelece entre elas. Esses tipos de prática constituem momentos de um mesmo processo, que é o processo formativo decorrente da necessidade de socialização da cultura e dos fins socioeducativos. Concebe-se que toda prática pedagógica é, em si mesma, uma prática educativa, mas a relação de correspondência inversa significaria, de acordo com o ponto de vista adotado neste trabalho, um erro categorial.

As práticas educativas se tornam pedagógicas quando passam a ser objeto de ação e reflexão no âmbito da pedagogia. Em termos homônimos, a ação e a reflexão pedagógica concretizam os objetivos educacionais mediante práticas organizadas sistematicamente desde sua concepção até seu estágio avaliativo. Concebe-se, então, que

[...] a prática pedagógica realiza-se por meio de sua ação científica sobre a práxis educativa, visando compreendê-la, explicitá-la a seus protagonistas, transformá-la mediante um processo de conscientização de seus participantes, dar-lhe suporte teórico, teorizar com os atores, encontrar na ação realizada o conteúdo não expresso das práticas. (Franco, 2012, p. 169).

O caráter configurado nas práticas educativas a partir da ação pedagógica se remete às relações de mediação entre os sujeitos, os saberes e os contextos dessas práticas. A tônica da reflexão pedagógica estaria, nessa perspectiva, na busca pela compreensão que aporta processos de decisão teórica, metodológica e técnica acerca dos elementos que podem ser mobilizados para produzir efeitos formativos qualificados, e tal compreensão é resultante da atitude reflexiva que relaciona os sujeitos que aprendem e ensinam, os saberes que se pretende ensinar e aprender e o contexto histórico, social e institucional mais amplo que envolve a situação educativa, inserindo-a numa complexa trama de relações que carregam contradições e possibilidades de formação humana. 
Reconhecer o caráter da ação pedagógica a partir desse ponto de vista implica considerar que "o pedagógico é, nesse sentido, um elemento relacional entre os sujeitos; portanto, é uma construção coletiva e não existe a priori, mas apenas na dialogicidade dos sujeitos da educação" (Franco, 2012, p. 169). Com efeito, o pedagógico se exprime como um sentido mediador que impregna a prática educativa de diretividade, podendo ser concebido também como "a direção de sentido, o rumo que se dá às práticas educativas [...]. É a análise pedagógica que explicita a orientação de sentido (direção) da prática educativa" (Libâneo, 2001, p. 135).

A ENE adquire caráter de processo pedagógico, nesse sentido, quando suas intencionalidades são explicitadas e configuram modos da ação sistematizados com base numa concepção pedagógica que relaciona finalidades e metodologias educativas, atuando como elemento mediador da sua realização como atividade humana inserida em múltiplos contextos.

Para transpor uma prática educativa não escolar ao terreno das práticas pedagógicas, torna-se necessário, inicialmente, o reconhecimento crítico das condições que organizam os contextos nos quais essa prática emerge, bem como a compreensão das intencionalidades explícitas e implícitas que dão sustentação aos seus objetivos. Diante disso, os agentes pedagógicos estabelecem, em sua práxis e em diálogo com as circunstâncias contextuais, os sentidos que reconfigurarão aquelas intencionalidades por meio da constituição de objetivos que estruturam a ação formativa.

De fato, a especificidade da prática educativa não escolar define elementos que devem ser considerados para a escolha quanto aos métodos e materiais necessários à operacionalização dos processos pedagógicos, à organização do espaço-tempo de formação e dos saberes, metas, perfis e parâmetros que deverão ser alcançados. Por esse motivo, o processo pedagógico de organização e execução de uma prática educativa não escolar é fortemente contextualizado, uma vez que, caso a especificidade do cenário e das circunstâncias que atravessam a prática fosse descaracterizada, tal processo poderia ser considerado como ilegítimo e perderia a capacidade de impactar efeitos formativos pretendidos pela mediação dos educadores.

A ENE consiste num vasto campo aberto à construção de processos pedagógicos que, por meio da práxis científica da pedagogia desdobrada pela reflexão na ação que materializa esses processos, certamente fornece elementos para que, progressivamente, sejam delineados setores em ENE e metodologias mais adequadas para cada um deles e, sobretudo, sejam formados repertórios de referências organizadas sobre aspectos de suas dinâmicas, público-alvo, conteúdos mais recorrentes e desafios postos à ação pedagógica.

Acredita-se que esse processo poderá fortalecer a ENE de tipo não formal como cenário de práticas pedagógicas e a produção de conhecimento acerca delas. Assumidas desse modo, as práticas em ENE poderão ser inseridas não apenas como campo de investigação, formação e prática em pedagogia, mas também como âmbito institucionalizado dos sistemas educativos, abarcando normativas que possibilitem seu reconhecimento e sua regulação para aumentar a qualidade de seus resultados e processo de 
gestão em inter-relação com as instituições escolares. Este último aspecto torna-se especialmente relevante quando se considera que

[...] o Brasil é um exemplo [...] nos quais a separação entre educação formal e não formal é estanque e nítida. Não só pela minuciosa regulamentação legal da primeira em contraste com a última, mas também devido ao alheamento entre ambas. (Ghanem Junior, 2008, p. 61).

Nessa perspectiva, é o reconhecimento da ENE como cenário de práticas pedagógicas profissionais que produz efeitos de institucionalização de processos de formação e atuação mais específicos. Assim, obtém-se clareza quanto aos saberes e competências para a formação profissional de pedagogos e educadores, em conformidade com a compreensão das especificidades desses processos.

\section{Algumas conclusões}

As instituições sociais de caráter formativo necessitam desenvolver mecanismos de fortalecimento de inter-relações quando se considera a importância de construir um projeto de sociedade com base em uma dinâmica educativa ampliada, em que as pessoas tenham oportunidade de aprender para se situarem de forma melhor quanto aos seus objetivos e para que a socialização de saberes e práticas culturais implique um contexto de maior participação e conscientização social. Essa dinâmica educativa se estrutura com base na diversidade de saberes em fluxo nas relações humanas, incorporando múltiplas possibilidades de promoção de aprendizagens significativas, por meio das quais as pessoas possam transferir conhecimentos adquiridos em contextos escolares e não escolares, com vistas à resolução de problemas.

Com efeito, as aprendizagens decorrentes dos processos vivenciados nos espaços de ENE nem sempre são reconhecidas como válidas ou são tidas como inferiores devido à hierarquia tradicional de saberes baseada na crença de que é mais importante o que se aprende em disciplinas científicas, artísticas e tecnológicas ministradas em instituições escolares. Do ponto de vista dos sistemas educativos, torna-se necessária a intensificação de iniciativas para a construção de parâmetros de reconhecimento e homologação das aprendizagens não escolares a serem aplicadas na avaliação de competências formativas e profissionais.

Por fim, importa dizer que a ENE como cenário de práticas pedagógicas se constrói pela ação dos profissionais da pedagogia e de demais educadores especializados, por meio da práxis científica e social operada a partir de concepções pedagógicas e do reconhecimento crítico e contextualizado da realidade que condiciona as práticas educativas. O empreendimento de dispositivos de reconhecimento e formação profissional de pedagogos para atuarem nesses cenários reveste-se de importância, uma vez que, além da abertura de novos espaços laborais, o exercício profissional pedagógico na ENE responde a demandas sociais concretas de formação humana, 
circunstância pela qual não se pode ignorar a relevância de aprofundar a discussão sobre a profissão de pedagogo e os processos de intervenção nesse âmbito como objeto conceitual, formativo e de trabalho em pedagogia.

\section{Referências bibliográficas}

BEILlEROT, J. A sociedade pedagógica. Porto: Rés, 1985.

COOMBS, P. H. A crise mundial da educação. São Paulo: Perspectiva, 1986.

CUADRADO ESCLAPEZ, T. La enseñanza que no se ve: educación informal en el siglo XXI. Madrid: Narcea, 2008.

DELORS, J. Educação: um tesouro a descobrir. 2. ed. São Paulo: Cortez, 1999.

FRANCO, M. A. S. Pedagogia e prática docente. São Paulo: Cortez, 2012. (Docência em Formação).

FREIRE, P.; HORTON, M. O caminho se faz caminhando: conversas sobre educação e mudança social. 4. ed. Petrópolis: Vozes, 2003.

GARCÍA ARETIO, L.; RUIZ CORBELLA, M.; GARCíA BLANCO, M. Claves para la educación: actores, agentes y escenarios en la sociedad actual. Madrid: UNED/Narcea, 2009.

GHANEM JUNIOR, E. G. G. Educação formal e não-formal: do sistema escolar ao sistema educacional. In: ARANTES, V. A. (Org.). Educação formal e não-formal. São Paulo: Summus, 2008. p. 59-89.

GOHN, M. da G. Educação não-formal e o educador social: atuação e desenvolvimento de projetos sociais. São Paulo: Cortez, 2010.

GUILE, D. O que distingue a economia do conhecimento? Implicações para a educação. Cadernos de Pesquisa, São Paulo, v. 38, n. 135, p. 611-636, set./dez. 2008.

LIBÂNEO, J. C. Pedagogia e pedagogos, para quê?. 4. ed. São Paulo: Cortez, 2001.

MEDINA RUBIO, R.; GARCÍA ARETIO, L.; RUIZ CORBELLA, M. Teoria de la educación: educación social. Madrid: Universidad Nacional de Educación a Distancia, 2008. 
PIMENTA, S. G.; ANASTASIOU, L. das G. C.; CAVALLET, V. J. Docência e ensino superior: construindo caminhos. In: BARBOSA, R. L. L. (Org.). Formação de educadores: desafios e perspectivas. São Paulo: Unesp, 2003. p. 267-278.

TOURIÑAN LOPEZ, J. M. Análisis teórico del carácter formal, no formal e informal de la educación. In: CONCEPTOS y propuestas: papers d'Educación. Valencia: [s. n.], 1983. p. 109-133.

TRILlA, J. A educação não-formal. In: ARANTES, V. A. (Org.). Educação formal e não-formal. São Paulo: Summus, 2008. p. 15-55.

TRILLA, J.; GROS, B.; LÓPEZ, F.; MARTÍN, M. J. La educación fuera de la escuela: ámbitos no formales y educación no-formal. Barcelona: Editorial Ariel, 2011.

Recebido em 17 de outubro de 2014.

Solicitação de correções em 27 de maio de 2015.

Aprovado em 2 de junho de 2015. 